International Journal of Advanced Trends in Computer Science and Engineering

Available Online at http://www.warse.org/IJATCSE/static/pdf/file/ijatcse11932020.pdf

https://doi.org/10.30534/ijatcse/2020/11932020

\title{
The Multiscale Image Processing Method from On-board Earth Remote Sensing Systems Based on the Artificial Bee Colony Algorithm
}

\author{
Hennadii Khudov', Sergey Glukhov ${ }^{2}$, Viacheslav Podlipaiev ${ }^{3}$, \\ Vladislav Pavlii ${ }^{4}$, Irina Khizhnyak ${ }^{5}$, Iryna Yuzova ${ }^{6}$ \\ ${ }^{1}$ Department of Radar Troops Tactic, Ivan Kozhedub Kharkiv National Air Force University, Kharkiv, Ukraine, \\ 2345kh_hg@ukr.net \\ ${ }^{2}$ Department of the Faculty of Postgraduate Education, Military Institute of Taras Shevchenko Kyiv National \\ University, Kyiv, Ukraine, gluhov1971@ukr.net \\ ${ }^{3}$ Department of the ontological systems and applied algebraic combinatorics Institute of Telecommunications and \\ Global Information Space Kyiv, Ukraine, pva_hvu@ukr.net \\ ${ }^{4}$ Department of Aviation Radiotechnical Systems of Navigation and Landing, Ivan Kozhedub Kharkiv National \\ Air Force University, Kharkiv, Ukraine, 2345kh_hg@ukr.net \\ ${ }^{5}$ Department of Mathematical and Software Automated Control Systems, Ivan Kozhedub Kharkiv National Air \\ Force University, Kharkiv, Ukraine, khizh_ia@ukr.net \\ ${ }^{6}$ Department of Reserve Officers Training, Ivan Kozhedub Kharkiv National Air Force University, Kharkiv, \\ Ukraine,uzik25@ukr.net
}

\begin{abstract}
The paper proposes the multiscale image processing method from on-board earth remote sensing systems based on the artificial bee colony algorithm. The advantages and disadvantages of image processing methods from remote sensing systems have been analyzed. The artificial bee colony algorithm is adaptive to environmental changes. It has multi-agency in implementation, and possibility of application for solution of both discrete and continuous optimization tasks. The original images with a different value of scale factor from the spacecraft Ikonos were processed. We have found that the use of the multiscale image processing method from on-board earth remote sensing systems based on the artificial bee colony algorithm reduces the number of "litter" objects.

For the correct operation of the complex, an automated technical diagnostic system is used. A procedure for the integrated use of diagnostic methods is proposed.
\end{abstract}

Key words : the multiscale image processing method, on-board Earth remote sensing systems, the artificial bee colony algorithm.

\section{INTRODUCTION}

It is known that Earth remote sensing data is very important for solving various problems for mapping terrestrial landscapes and infrastructures, managing natural resources, the military research, studying environmental changes, and so on [1]-[3].

High-resolution satellite imagery materials are one of the most efficient and reliable sources of information [1]-[3].The most urgent task of decoding satellite imagery materials is the process of selecting objects of interest in the image [1], [3]. Known image processing methods from on-board earth remote sensing systems are reduced to solving problems of threshold selection [4], [5], classification [6], clustering [7]-[9] and the selection of finite elements [10], [11].

Known methods are certainly effective, however, when processing complexly structured images, the quality requirements for highlighting objects of interest are not always met. For example, the known methods do not provide the required error values of the first and second kind when processing complex structured images from the space systems of remote sensing of the Earth.

Thus, the development of a image processing method from onboard earth remote sensing systems is relevant. The main purpose of image processing is to highlight objects of interest against the background of noise.

\subsection{Problem analysis}

Image processing of remote sensing systems has been considered in many papers. The papers differs in the formulation of the problem or task, the research methods, the criteria and the performance evaluation indicators. 
Methods based on choosing the optimal threshold for detecting objects of interest from the background are presented in [1]-[3], [8], [12]. The disadvantage of threshold processing methods, for example, the Otsu method, is the dependence of the processing result from the image brightness.

In [13], [14], methods for isolating the contours of objects in images were considered: the methods of Prewitt, Kirsch, Wallis, Sobel, and Canny. The main disadvantages of methods [13], [14] are the presence of contour discontinuities, a significant dependence on the noise level, and computational complexity.

In paper [15] methods of locality adaptive discriminant analysis for spectral-spatial classification of hyperspectral images were developed. However, classification methods do not apply to image processing methods and can be applied later.

In papers [7]-[9] methods of clustering analysis for hyperspectral images of remote sensing systems. The main method is the k-means method for segmentation of images. The results of k-means method depend on type of an image and initial parameters. Secondly, a result of clustering is achieved as a result of multiple iterations. These disadvantages of the k-means method complicate image processing in the real time.

In papers [10], [11] a hierarchical sparsity unmixing method to address endmember variability in hyperspectral image and the methods for endmember extraction from hyperspectral images and are developed. Methods [10], [11] do not solve the problem of detecting of objects against a background of noise.

In papers [4], [12] swarm methods for images segmentation from on-board optoelectronic remote surveillance systems were developed. In paper [4], [12] methods for determining the edges of objects on tone aerospace images based on ant colony optimization algorithms were developed. The main disadvantage of the ant colony optimization algorithms is a large number of contours of small-sized objects ("litter" objects).

In paper [9] methods for determining urban infrastructure objects elements on the results from air monitoring were developed. Methods [9] are intended to detect only the contours of the elements of urban infrastructure. Such objects, as a rule, have an extended shape and consist of many geometric primitives, for example, straight lines.

In paper [4] method for optical electronic images from on-board systems of remote sensing of the Earth segmentation by the artificial bee colony method was developed. The method of artificial bee colony to find global optimums of complex functions, for example, Schweffel function, Rastrigin function, spherical function, was used. The artificial bee colony method is adaptive to environmental changes, has multi-agency in implementation, and possibility of application for solution of both discrete and continuous optimization tasks. The better solution is the result of decisions of all agents (bees).

In papers [16] the method for multiscale image processing based on the ant colony optimization algorithm was developed. The using the method [16] increase the quality of object detection. The main disadvantage of method [16] is a slight decrease in "litter" objects, significant time costs, and local optima of the fitness function.

The purpose of the article is to develop the multiscale image processing method from on-board Earth remote sensing systems based on the artificial bee colony algorithm.

\section{MAIN MATERIAL}

The essence of multiscale transformation of image is shown in Figure 1.

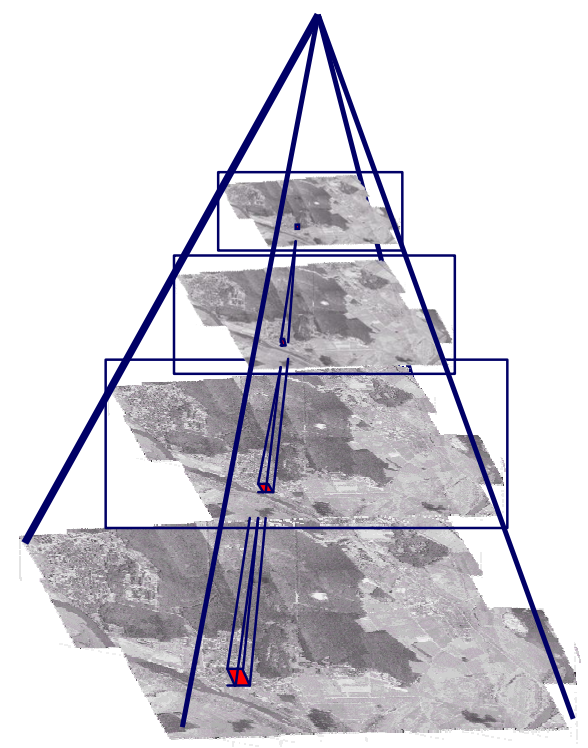

Figure 1: The essence of multiscale transformation of image

Multiscale transformation of the image $f(x, y)$, where $(x, y)-$ the spatial coordinates of the image will be presented by expression (1):

$$
\mathrm{L}\left(\mathrm{x}, \mathrm{y}, \mathrm{K}_{\mathrm{m}}\right)=\mathrm{g}\left(\mathrm{x}, \mathrm{y}, \mathrm{K}_{\mathrm{m}}\right) * \mathrm{f}(\mathrm{x}, \mathrm{y})
$$

where $(\mathrm{x}, \mathrm{y})$ is the coordinates of the pixels of image; $\mathrm{L}(\mathrm{x}, \mathrm{y}, \mathrm{t})$ is multiscale transformation of the image $f(x, y)$; $g(x, y, t)$ is core of the transformation; $\mathrm{K}_{\mathrm{m}}$ is the scale factor; * is the operator of the convolution.

The core of the transformation $\mathrm{g}\left(\mathrm{x}, \mathrm{y}, \mathrm{K}_{\mathrm{m}}\right)$ will choose by expression (2) as Gaussians (Figure 2): 


$$
\mathrm{g}\left(\mathrm{x}, \mathrm{y}, \mathrm{K}_{\mathrm{m}}\right)=\frac{1}{2 \pi \mathrm{K}_{\mathrm{m}}} \mathrm{e}^{-\frac{\left(\mathrm{x}^{2}+\mathrm{y}^{2}\right)}{2 \mathrm{~K}_{\mathrm{m}}}} .
$$

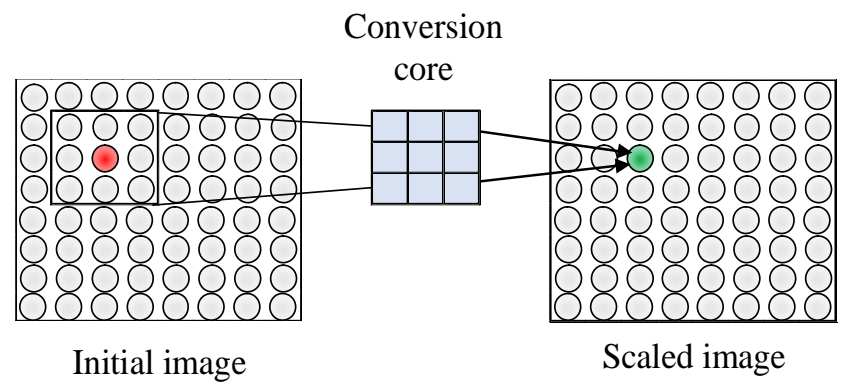

Figure 2: The principle of scaled image acquisition

The Gaussian type of core transformation is uniqueness type. The uniqueness of Gaussians core includes invariance to mudslide, linearity, invariance to scale and distortion invariance to rotation of the image.

The objects of interest are on the images with a different value $\mathrm{Km}$. That's why the features of objects can be in the images of multiple scales. The improvement of quality of multiscale processing of images from on-board earth remote sensing systems is based on that.

The scheme of the multiscale image processing method from on-board Earth remote sensing systems based on the artificial bee colony algorithm is shown in Figure 3 . According to the Figure 3 the multiscale image processing method from on-board Earth remote sensing systems includes the next stages.

1. Enter the next source data: $f_{K_{m}}(X)$ - the image of scale $\mathrm{K}_{\mathrm{m}} ;\left|\mathrm{S}_{\mathrm{K}_{\mathrm{m}}}\right|$ - the number of agents on the image of scale $\mathrm{K}_{\mathrm{m}}$; $\mathrm{n}_{\mathrm{K}_{\mathrm{m}}}^{\mathrm{s}}$ - the number of spy agents on the first iteration on the image of scale $\mathrm{K}_{\mathrm{m}} ; \mathrm{n}_{\mathrm{K}_{\mathrm{m}}}^{\mathrm{b}}$ - the number of the best positions of agents on the image of scale $\mathrm{K}_{\mathrm{m}} ; \mathrm{n}_{\mathrm{K}_{\mathrm{m}}}^{\mathrm{g}}$-the number of perspective positions on the image of scale $\mathrm{K}_{\mathrm{m}} ; \mathrm{c}_{\mathrm{K}_{\mathrm{m}}}^{\mathrm{b}}$ - is the number of agents, which migrate to the best positions on the image of scale $\mathrm{K}_{\mathrm{m}} ; \mathrm{c}_{\mathrm{K}_{\mathrm{m}}}^{\mathrm{g}}$-the number of agents, which migrate to perspective positions on the image of scale $\mathrm{K}_{\mathrm{m}}$; $\operatorname{rad}_{\mathrm{K}_{\mathrm{m}}}$ - the coefficient on the image of scale $\mathrm{K}_{\mathrm{m}} ; \mathrm{rx}_{\mathrm{K}_{\mathrm{m}}}, \mathrm{ry}_{\mathrm{K}_{\mathrm{m}}}$-the sizes of neighborhoods of the best and perspective positions by the coordinates $\mathrm{x}$ and $\mathrm{y}$ on the image of scale $\mathrm{K}_{\mathrm{m}}$.

2. The processing the images $\mathbf{f}_{\mathrm{K}_{\mathrm{m}}}(\mathbf{X})$ by the artificial bee colony algorithm, the getting a sequence of images $\mathbf{f s}_{\mathrm{K}_{\mathrm{m}}}(\mathbf{X})$ with a different value of scale factor $\mathrm{K}_{\mathrm{m}}$.
3. The getting the rescale sequence with different value of scale factor $\mathrm{K}_{\mathrm{m}}$ of images $\mathbf{f s}_{\mathrm{K}_{\mathrm{m}}}(\mathbf{X})$ to the initial scale $\left(\mathrm{K}_{\mathrm{m}}=1\right)$.

4. The calculating the image-filter $\mathrm{f}_{\mathrm{f}}(\mathbf{X})$ by expression (3):

$$
\mathrm{f}_{\mathrm{f}}(\mathbf{X})=\frac{\sum_{\mathrm{m}=1}^{\mathrm{N}} \mathrm{fs}_{\mathrm{K}_{\mathrm{m}}}(\mathbf{X})}{\mathrm{N}},
$$

where $\mathrm{N}$ is the number of scaled images.

5. The determining of the resulting image $\mathrm{fs}_{\mathrm{R}}(\mathbf{X})-$ pixelwise product of image $\mathrm{f}_{\mathrm{K}_{1}}(\mathbf{X})$ and the image-filter $\mathrm{f}_{\mathrm{f}}(\mathbf{X})$ by expression (4):

$$
\mathrm{fs}_{\mathrm{R}}(\mathbf{X})=\mathrm{f}_{\mathrm{K}_{\mathrm{l}}}(\mathbf{X}) \& \mathrm{f}_{\mathrm{f}}(\mathbf{X}),
$$

where \& is the "logical multiplication".

Thus, the objects' pixels are on the resulting image $\mathrm{fs}_{\mathrm{R}}(\mathbf{X})$ only if the objects' pixels are present on all images with a different scale value $\mathrm{Km}$.

6. The getting the resulting image $\mathrm{fs}_{\mathrm{R}}(\mathbf{X})$.

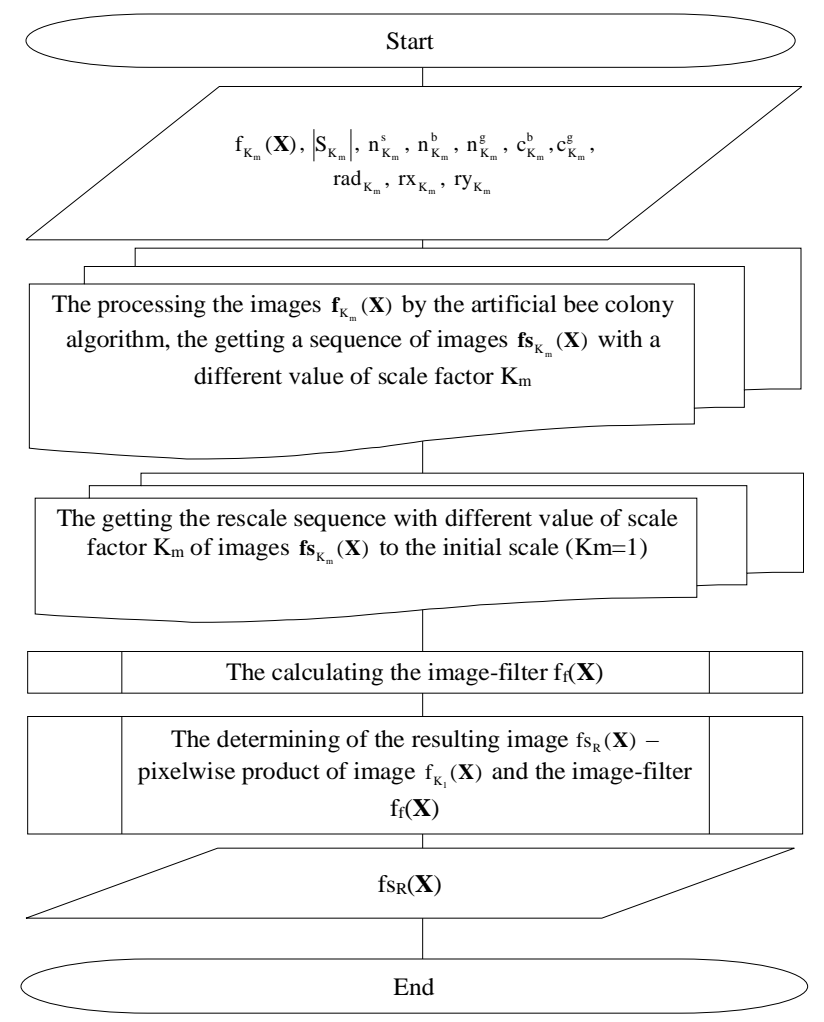

Figure 3: Scheme of the multiscale image processing method from on-board Earth remote sensing systems based on the artificial bee colony algorithm 
The processing the each images $\mathbf{f}_{\mathrm{K}_{\mathrm{m}}}(\mathbf{X})$ with a different value of scale factor $\mathrm{K}_{\mathrm{m}}$ by the artificial bee colony algorithm shows on Figure 4.

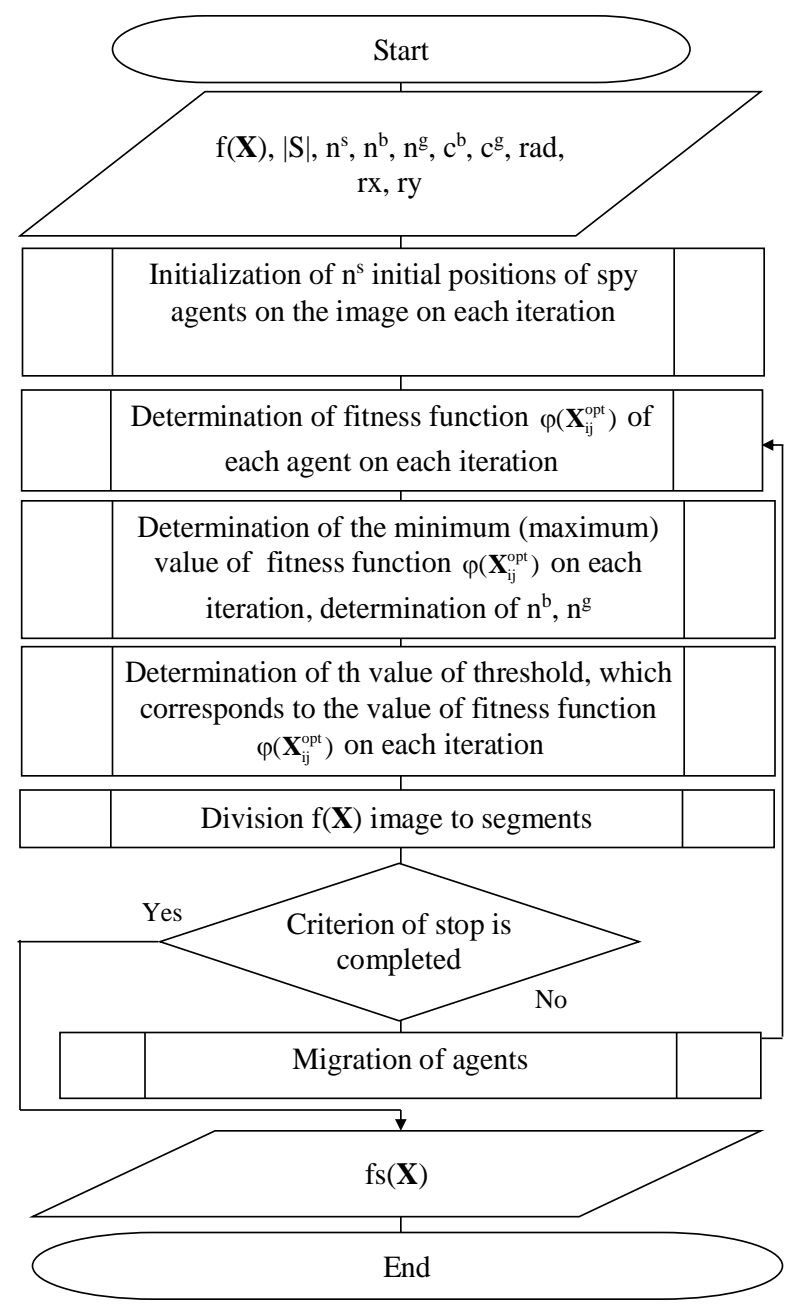

Figure 4: Scheme processing the each images $\mathbf{f}_{\mathrm{K}_{\mathrm{m}}}(\mathbf{X})$ with a different value of scale factor $\mathrm{K}_{\mathrm{m}}$ by the artificial bee colony algorithm

The original images with a different value of scale factor $\mathrm{K}_{\mathrm{m}}$ $\left(\mathrm{K}_{\mathrm{m}}=1,2,4,8,16,32,64,128\right)$ are on the Figure 5. This is image from the spacecraft Ikonos (DigitalGlobe company, the United States of America) [18]. The images (Figure 5) are presented in color space Red-Green-Blue (RGB). The artificial bee colony algorithm parameters are on Table 1.

The rescale sequence with different value of scale factor $\mathrm{K}_{\mathrm{m}}$ of images $\mathbf{f s}_{\mathrm{K}_{\mathrm{m}}}(\mathbf{X})$ to the initial scale $\left(\mathrm{K}_{\mathrm{m}}=1\right)$ are on Figure 6.

The calculating the image-filter $f_{f}(\mathbf{X})$ by expression (3) is shown on Figure 7.
The determining of the resulting image $\mathrm{fs}_{\mathrm{R}}(\mathbf{X})$ - pixelwise product of image $f_{K_{1}}(\mathbf{X})$ and the image-filter $f_{f}(X)$ by expression (4) is shown on Figure 8.
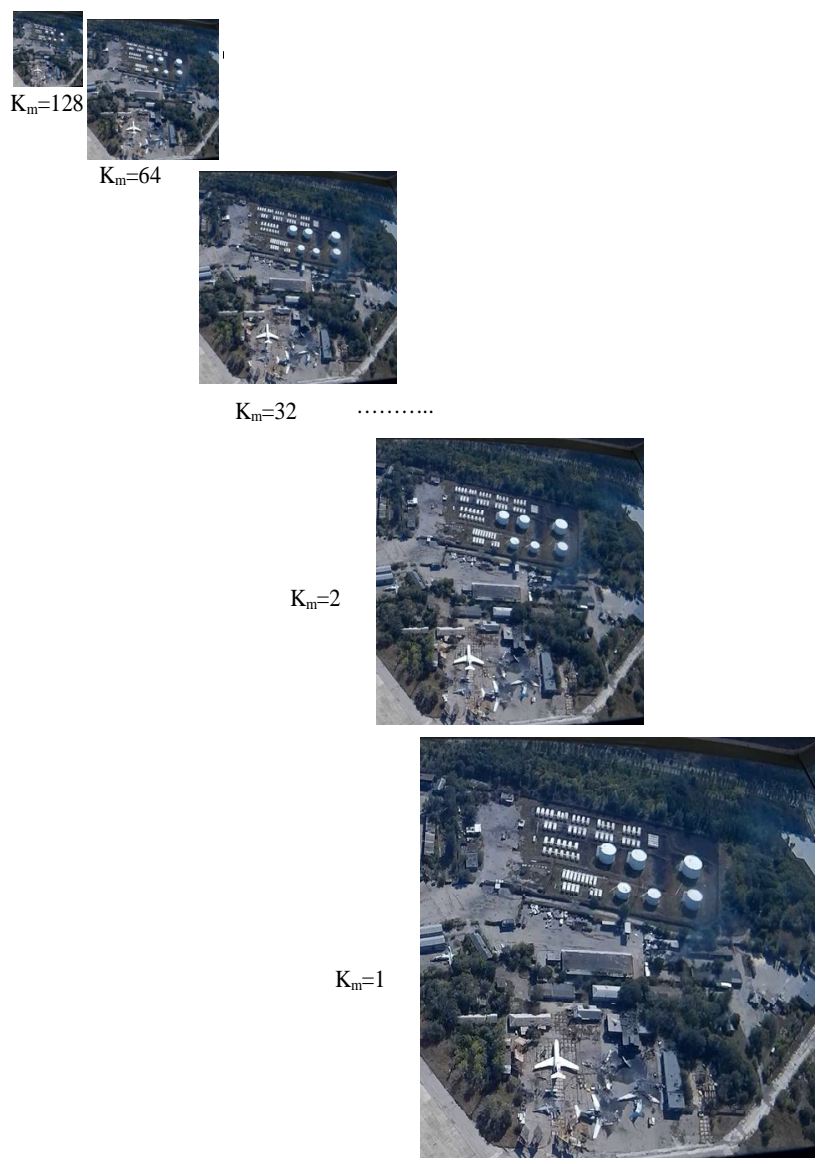

Figure 5: The original images with a different value of scale factor $\mathrm{Km}(\mathrm{Km}=1,2,4,8,16,32,64,128)$

Table 1: Artificial Bee Colony Algorithm Parameters

\begin{tabular}{|c|c|}
\hline Parameter Name & Parameter Value \\
\hline$\left|\mathrm{S}_{\mathrm{K}_{\mathrm{m}}}\right|$, & 100 \\
\hline $\mathrm{n}_{\mathrm{K}_{\mathrm{m}}}^{\mathrm{s}}$ & 20 \\
\hline $\mathrm{n}_{\mathrm{K}_{\mathrm{m}}}^{\mathrm{b}}$ & 5 \\
\hline $\mathrm{n}_{\mathrm{K}_{\mathrm{m}}}^{\mathrm{g}}$ & --- \\
\hline $\mathrm{c}_{\mathrm{K}_{\mathrm{m}}}^{\mathrm{b}}$ & 80 \\
\hline $\mathrm{c}_{\mathrm{K}_{\mathrm{m}}}^{\mathrm{g}}$ & -- \\
\hline $\operatorname{rad}_{\mathrm{K}_{\mathrm{m}}}$ & 2 \\
\hline $\mathrm{rx}_{\mathrm{K}_{\mathrm{m}}}$ & 5 \\
\hline $\mathrm{ry}_{\mathrm{K}_{\mathrm{m}}}$ & 5 \\
\hline
\end{tabular}

Figure 7 and Figure 8 were got using the high-level programming language and interactive environment for programming, numerical calculations and visualization of results MATLAB R2017b. 

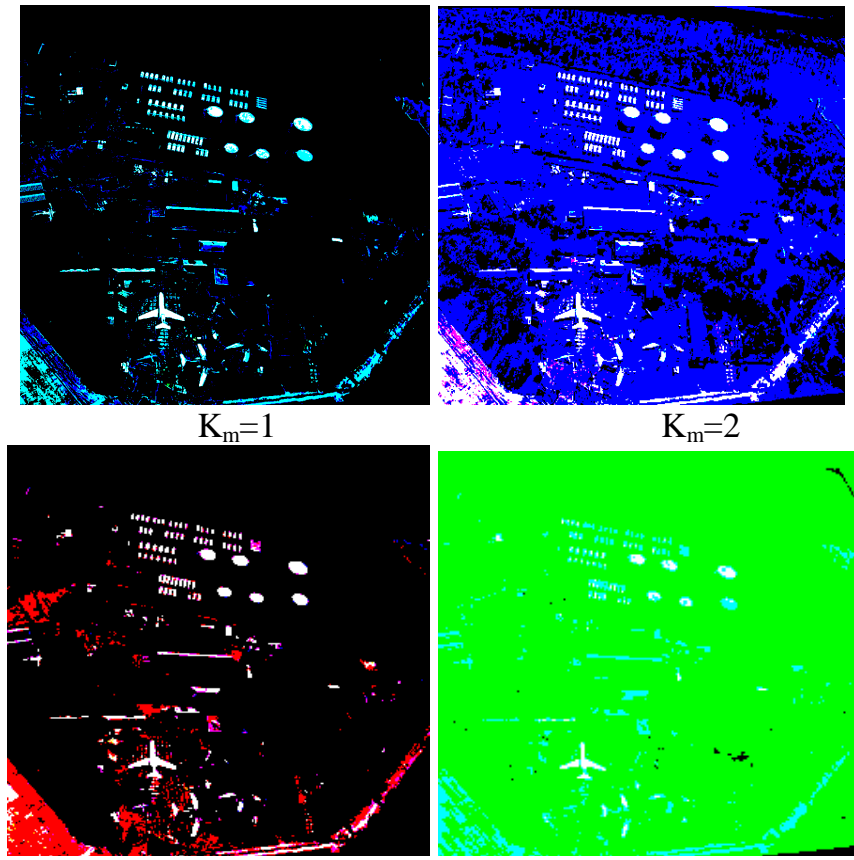

$\mathrm{K}_{\mathrm{m}}=4$

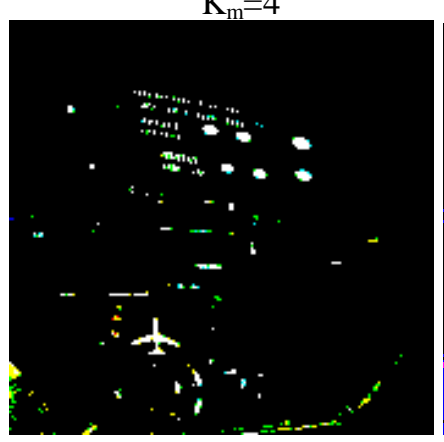

$\mathrm{K}_{\mathrm{m}}=16$

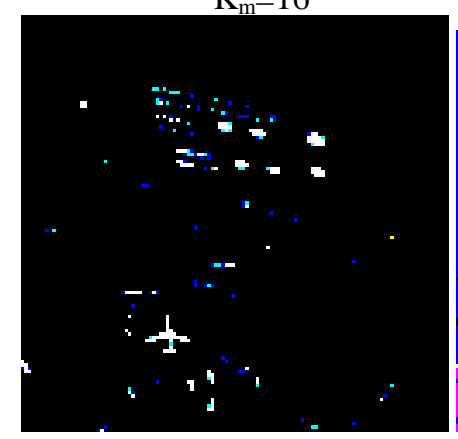

$\mathrm{K}_{\mathrm{m}}=64$

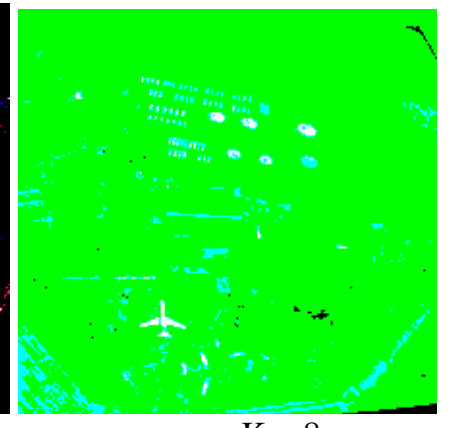

$\mathrm{K}_{\mathrm{m}}=8$

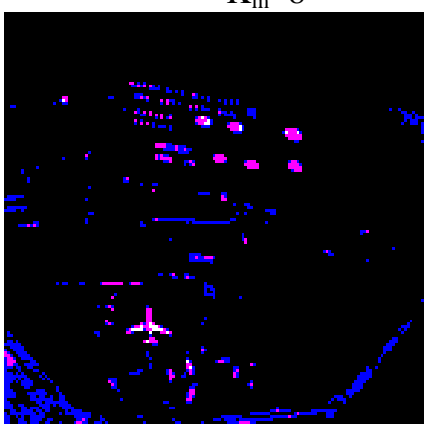

$\mathrm{K}_{\mathrm{m}}=32$

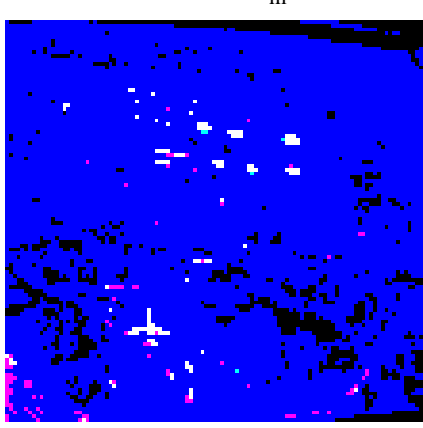

$\mathrm{K}_{\mathrm{m}}=128$

Figure 6: The rescale sequence with different value of scale factor $\mathrm{K}_{\mathrm{m}}$ of images $\mathbf{f s}_{\mathrm{K}_{\mathrm{m}}}(\mathbf{X})$ to the initial scale $\left(\mathrm{K}_{\mathrm{m}}=1\right)$

We have found that the use of the multiscale image processing method from on-board earth remote sensing systems based on the artificial bee colony algorithm reduces the number of "litter" objects.

The multiscale image processing method from on-board earth remote sensing systems based on the artificial bee colony algorithm is implemented by a special software and image processing complex.

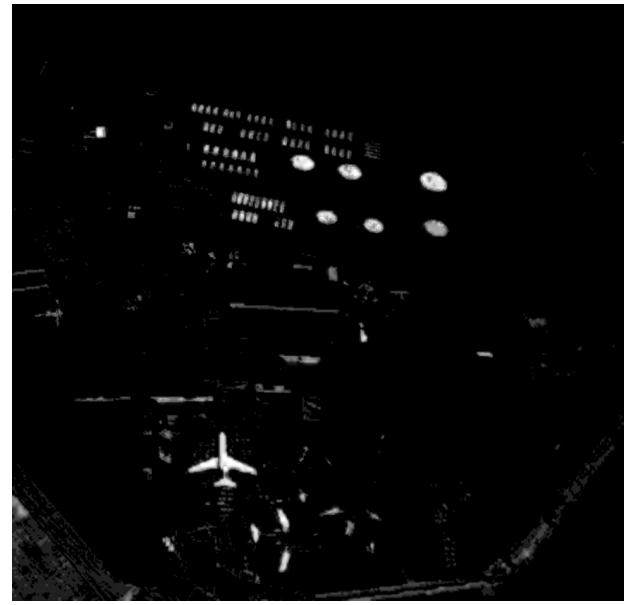

Figure 7: The rescale The calculating the image-filter $\mathrm{f}_{\mathrm{f}}(\mathbf{X})$ by expression (3)

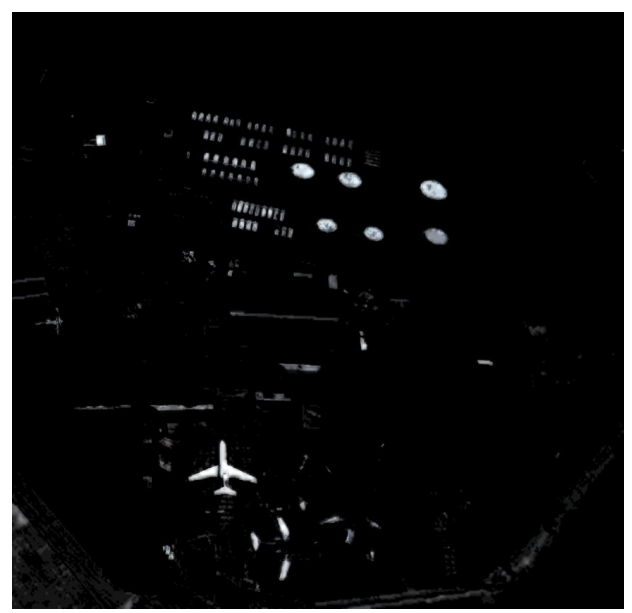

Figure 8: The rescale The determining of the resulting image $\mathrm{fs}_{\mathrm{R}}(\mathbf{X})$ - pixelwise product of image $\mathrm{f}_{\mathrm{K}_{1}}(\mathbf{X})$ and the image-filter $\mathrm{f}_{\mathrm{f}}(\mathbf{X})$ by expression (4)

For the correct operation of the complex it is necessary to ensure the functioning of technical diagnostics. An automated system of technical diagnostics should be used for this [17].

The procedure for integrated use of diagnostic methods is proposed as follows:

- power connection;

- connect the digital bus enclosure to the diagnostic device;

- submit test tests to the input of the digital device from the output of the test sequence generator;

- determination of values of diagnostic parameters for each method;

- signal output from the intelligent diagnosis system to the input of the control unit of the switch;

- signal output from the intelligent diagnostics system to the input of the diagnostic device and output of test sequences to the input of the digital device;

- receiving data and recording to a computer;

- admission of data to the intellectual diagnosis system and recording it in the knowledge base;

- comparison of the obtained data with the reference data; 
- determination of the technical condition of the digital device;

- forecasting the technical condition;

- determination of residual resource;

- determining the time of the next inspection.

\section{CONCLUSION}

In this paper the multiscale image processing method from on-board earth remote sensing systems based on the artificial bee colony algorithm is proposed. The advantages and disadvantages of image processing methods from remote sensing systems have been analyzed. The artificial bee colony algorithm is adaptive to environmental changes, has multi-agency in implementation, and possibility of application for solution of both discrete and continuous optimization tasks. The original images with a different value of scale factor from the spacecraft Ikonos were processed. We have found that the use of the multiscale image processing method from on-board earth remote sensing systems based on the artificial bee colony algorithm reduces the number of "litter" objects

For the correct operation of the complex, an automated technical diagnostic system is used. A procedure for the integrated use of diagnostic methods is proposed.

Areas of further research are comparison of the developed method with existing and to conctruct the multiscale image processing method from on-board earth remote sensing systems based on the others swarm algorithms.

\section{REFERENCES}

1. S. Pisupati and M. Ismail, Image Registration Method for Satellite Image Sensing using Feature based Techniques, IJATCSE, Vol. 9. № 1, 2020, pp. 590-593. DOI: https://doi.org/10.30534/ijatcse/2020/82912020.

2. H. Khudov et al., The Efficiency Estimation Method of Joint Search and Detection of Objects for Surveillance Technical Systems, International Journal of Emerging Trends in Engineering Research, Vol. 8. № 3, 2020, pp. 813-819.

DOI: https://doi.org/10.30534/ijeter/2020/34832020.

3. J. A. Richards, Remote Sensing Digital Image Analysis. Springer, 2013, 503 p.

4. I. Ruban et al., Segmentation of opticalelectronic images from on-board systems of remote sensing of the Earth by the artificial bee colony method, EEJET, № 2/9 (98), 2019, pp. 37-45. DOI: https://doi.org/10.15587/1729-4061.2019.161860.

5. H. Khudov et al., Method of Radar Adjustment with Automatic Dependent Surveillance Technology Use, in PIC S\&T, 2019, pp. 402-406.

DOI:https://doi.org/10.1109/PICST47496.2019.9061245
6. H. Khudov et al., The Bayes Rule of Decision Making in Joint Optimization of Search and Detection of Objects in Technical Systems, International Journal of Emerging Trends in Engineering Research, № 8(1), 2020, pp.

$7-12$.

DOI: https://doi.org/10.30534/ijeter/2020/02812020.

7. H. Khudov et al., Development of methods for determining the contours of objects for a complex structured color image based on the ant colony optimization algorithm, Eureka: Physics and Engineering, № 1, 2020, pp. 34-47. DOI: https://doi.org/10.21303/2461-4262.2020.001108.

8. I. Ruban et al., Segmentation of the images obtained from onboard optoelectronic surveillance systems by the evolutionary method, EEJET, № 5/9 (89), 2017, pp. 49-57.

DOI: https://doi.org/10.15587/1729-4061.2017.109904.

9. I. Ruban et al., Method for determining elements of urban infrastructure objects based on the results from air monitoring, EEJET, № 4/9 (100), 2019, pp. 52-61. DOI: https://doi.org/10.15587/1729-4061.2019.174576.

10. B. Zhang et al., Improvements in the ant colony optimization algorithm for endmember extraction from hyperspectral images, IEEE J. Sel. Top. Appl. Earth Obs. Remote Sens. 2013, № 6, pp. 522-530.

11. J. Zou et al., A hierarchical sparsity unmixing method to address endmember variability in hyperspectral image, Remote Sens. Basel 2018, № 10, 738 p.

12. I. Ruban et al., A Swarm Method for Segmentation of Images Obtained from On-Board Optoelectronic Surveillance Systems, in PIC S\&T, 2018, pp. 613-618. DOI: https://doi.org/10.1109/infocommst.2018.8632045.

13. I. Ruban et al., Construction of methods for determining the contours of objects on tonal aerospace images based on the ant algorithms, EEJET, № 5/9 (101), 2019, pp. 25-34. DOI: https://doi.org/10.15587/1729-4061.2019.177817.

14. V. Mashtalir, I. Ruban, and V. Levashenko (Eds.), Advances in Spatio-Temporal Segmentation of Visual Data, Springer, 2020, 274 p. DOI: https://doi.org/10.1007/978-3-030-35480-0.

15. Q. Wang, Z. Meng and X. Li, Locality adaptive discriminant analysis for spectral-spatial classification of hyperspectral images, IEEE Geosci. Remote Sens. Lett., 2017, № 14, pp. 2077-2081.

16. I. Ruban et al., The Method for Selecting the Urban Infrastructure Objects Contours, in PIC S\&T, 2019, pp. 689-693.

DOI:https://doi.org/10.1109/PICST47496.2019.9061267

17. I. Ruban et al., The Calculating Effectiveness Increasing of Detecting Air Objects by Combining Surveillance Radars into The Coherent System, IJETER, Vol. 8. № 4, 2020, pp. 1295-1301. DOI: https://doi.org/10.30534/ijeter/2020/58842020.

18. Ikonos Satellite Image Gallery, URL: http://www.satimagingcorp.com/gallery/ikonos/ (accessed 12 November 2019). 